\title{
Wacana Politik dan Diskriminasi dalam Kumpulan Cerita Pendek Pao An Tui Karya Dwicipta
}

\author{
Yudhistira Adi Prasetya \\ Universitas Negeri Yogyakarta \\ yudhistiraadi@gmail.com
}

\begin{abstract}
Abstrak
Penelitian ini bertujuan mendeskripsikan konteks historis, wacana politik, dan wacana diskriminasi dalam kumcer Pao An Tui karya Dwicipta. Pengumpulan data diakukan dengan teknik simak-catat. Analisis data dilakukan dengan teknik deskriptif kualitatif. Validasi data menggunakan validitas semantik. Hasil penelitian menunjukkan 1) Keberadaan Pao An Tui di Indonesia tidak bisa dipisahkan dari sejarah orang-orang China yang berlayar untuk mencari rumah tinggal baru, 2) Pao An Tui sangat kenal dengan nuansa politis, khususnya sebagai alat politik Belanda KNIL untuk menghalau mata-mata pribumi, dan 3) terdapat diskriminasi dan teror yang dialami oleh masyarakat China secara fisik dan psikologis.
\end{abstract}

Kata kunci: analisis wacana, diskriminasi, cerita pendek, politik

\begin{abstract}
This study aims to describe 1) the historical context in Pao An Tui's work by Dwicipta; 2) political discourse in Dwikipta's Pao An Tui short story; 3) discrimination discourse in Dwikipta's Pao An Tui short story. The technique of collecting data uses reading techniques and note taking techniques. The data analysis technique used is descriptive qualitative. Data validation uses semantic validity. The results of the study: 1) the formation of the Pao An Tui in Indonesia cannot be separated from a concern of the Chinese people for their survival on overseas lands; 2) the formation of Pao An Tui was thick with political nuances, especially as a political tool of the Dutch KNIL to ward off bumiputera spies; 3) there is discrimination and terror which is experienced by ethnic Chinese physically and psychologically.
\end{abstract}

Keywords: discourse analysis, discrimination, short story, politic

\section{PENDAHULUAN}

Cerpen Pao An Tui karya Dwicipta merupakan salah satu cerpen pilihan yang diterbitkan oleh Kompas Gramedia sebagai salah satu karya terbaik yang menggambarkan konteks sejarah kelam bangsa Indonesia. Pao An Tui menceritakan pergerakan kaum minoritas (baca: etnis China) di Indonesia 
pada masa-masa awal kemerdekaan. Pao An Tui atau Barisan Polisi Keamanan Kota, suatu penjaga keamanan sipil yang dibentuk etnis China di tahun 1947 guna menjaga keselamatan orang-orang China, baik karena ancaman Belanda maupun pihak-pihak Republik yang tidak menyukainya. Dibentuknya Pao An Tui tidak terlepas dari banyaknya penindasan, kekerasan, dan diskriminasi kaum mayoritas (baca: bumiputera) terhadap kaum minoritas ini di berbagai daerah (Dwicipta, 2005).

Cerpen Pao An Tui membawa kita untuk memahami dan mengetahui kondisi kelam bangsa kita pada masa awal kemerdekaan. Cerpen merupakan bagian dari komunikasi massa, merujuk pada pendapat Gerbner (via Ardianto, 2004: 4) bahwa komunikasi massa adalah produksi dan distribusi yang berlandaskan teknologi dan lembaga dari arus pesan yang kontinyu serta paling luas dimiliki orang dalam masyarakat industri. Pengertian proses komunikasi massa pada hakikatnya merupakan proses penyampaian lambanglambang yang berarti, yang dilakukan melalui saluran (channel), biasanya dikenal dengan media printed (press), media auditif (radio), media visual (gambar, lukisan) atau media audio visual (televisi dan film).

Media yang dimaksud adalah alat yang dapat digunakan untuk mencapai massa. Komunikasi massa menggunakan media massa dalam menyampaikan sebentuk informasi yang akan disampaikan. Melalui media massa, manusia menyampaikan pemikiran-pemikirannya, begitu pula dengan cerpen yang menjadi medium bagi penulisnya dalam menyampaikan pemikiran dan dapat juga mengukuhkan ideologi dominan di masyarakat. Wacana sastra adalah bentuk ideologi atau pencerminan dari ideologi tertentu. Ideologi ini dikonstruksi oleh kelompok yang dominan dengan tujuan untuk mereproduksi dan melegimitasi dominasi mereka. Salah satu strateginya adalah membuat kesadaran khalayak, bahwa dominasi itu diterima secara taken for granted.

Menurut Sumardjo dan Saini (1996: 6), karya sastra dibedakan menjadi dua genre yaitu fiksi populer dan fiksi sastra. Kedua jenis sastra tersebut dibedakan dan dinilai berdasarkan segi mutu sastra, ada dua hal yang membedakannya. Pertama, fiksi populer dituntut untuk memberikan hiburan ringan sedangkan fiksi sastra dituntut untuk memberikan pemahaman hidup secara lebih luas dan mendalam. Kedua, fiksi populer bersifat eskapisme, yakni melepaskan diri dari kenyataan hidup dan persoalan hidup seharihari. Sedangkan fiksi sastra, pembaca diajak untuk mendekatkan diri pada persoalanpersoalan hidup sehingga mereka dapat memahami kehidupan ini secara lebih mendalam. Berdasarkan perbedaan sastra tersebut, cerpen Pao An Tui masuk ke dalam golongan fiksi sastra karena penulis cerpen ini mengisahkan mengenai kekerasan dan penindasan yang dialami kaum minoritas China di Indonesia.

Dwicipta menyampaikan banyak hal dalam cerpen Pao An Tui. Salah satunya tentang kesewenang-wenangan kaum mayoritas (bumiputera) terhadap minoritas China yang ingin menunjukkan ego dan kekuasaannya. Cerita diawali dengan terbunuhnya A Siong, anak Keng Hong, seorang anggota Pao An Tui yang dianggap pengkhianat oleh Republik. Keberadaan etnis 
China di Indonesia menempati posisi yang sulit pada masa itu. Pao An Tui yang dibentuk pada masa Belanda tersebut, yang tujuan awalnya adalah sebagai pelindung bagi warga China itu sendiri, pada masa setelah kemerdekaan justru dianggap sebagai gerakan pengkhianatan yang menimbulkan sentimen dan diskriminasi.

\section{KONTEKS SEJARAH DALAM PAO AN} TUI

Setelah Jepang bertekuk lutut kepada sekutu yang menjadi pemenang pada laga Perang Dunia II. Indonesia sebagai bangsa yang terjajah mulai bangkit untuk menjalani babak baru menjadi sebuah entitas politik yang berdaulat dan berusaha sejajar dengan negaranegara manapun di dunia. Tanggal 17 Agustus 1945 menjadi tonggak awal revolusi nasional bangsa Indonesia yang ditandai dengan dicetuskannya Proklamasi Kemerdekaan oleh Soekarno-Hatta. (Kahin, 1990: 11)

Bertolak dari proklamasi kemerdekaan tersebut, di berbagai daerah hampir bersamaan muncul gerakan-gerakan pendaulatan di mana targetnya tak lebih dari sisa-sisa pendukung tatanan kolonial Belanda dan pendudukan Jepang yang tercipta belakangan (Cribb, 1990: 7). Aksi "pembersihan" secara sepihak yang terjadi di daerah tidak hanya menyapu kalangan atas saja - di mana sebelumnya rajaraja tradisional, para bangsawan kecil dan kelompok birokrat memiliki pengaruh di masa-masa sebelum kemerdekaan-, tetapi juga menimpa kalangan bawah, terutama orang-orang Indo dan Tionghoa. Tindakan tersebut dapat terjadi karena respons dari masyarakat bumiputra yang menganggap orang Tionghoa memiliki "hubungan" dengan
Belanda -meskipun di Medan gerakan protes untuk meminta perlindungan kepada sekutu baru muncul setelah aksi kekerasan terjadi. Di Surabaya sendiri perlawanan terhadap pandangan buruk tersebut ditunjukkan oleh komunitas Tionghoa di kota itu dengan turut aktif dalam perjuangan melawan Belanda. Akan tetapi, kekerasan tetap merupakan fenomena tersendiri pada masa-masa awal revolusi Indonesia.

Tibanya sekutu guna mengambil alih kekuasaan Jepang di Indonesia ternyata menimbulkan tantangan-tantangan serius yang pertama terhadap revolusi. Inggris yang menjadi penanggung jawab pendaratan sekutu di wilayah Asia Tenggara ternyata tidak sendiri, mereka diboncengi oleh NICA (Netherlands Indies Civil Administration). Diawali dari pendaratan pertama di bulan September 1945, pasukan sekutu (Inggris dan NICA) berhasil masuk ke Jakarta untuk melepaskan kaum internir-an Jepang. Keadaan ini seringkali memicu bentrokan senjata dengan badan perjuangan setempat. Revolusi Nasional yang dimulai dari Jakarta rupanya merembet hingga ke kota-kota besar lainnya di Jawa dan Sumatra, kembalinya penguasa lama menjadi ancaman laten terhadap kemajuankemajuan yang telah dicapai oleh pihak Republik.

Masa Bersiap, begitulah pemuda-pemuda revolusioner menyebutnya sangat terasa pengaruhnya di Surabaya. Pada akhir Oktober 1945, sekitar enam ribu prajurit sekutu yang terdiri dari serdadu Inggris, Gurkha, dan anggota NICA mendarat di kota ini. Kehadiran mereka membuat keadaan semakin tegang dan tak menentu. Seperti di Jakarta, alih-alih membebaskan tawanan perang, pihak Belanda 
rupanya juga mempersenjatai para tawanan dan mempengaruhi etnis Tionghoa di kota ini untuk memihak mereka guna membangun kembali kekuasaannya (Roeslan Abdulgani, 1973: 23). Strategi ini rupanya berhasil, di mana beberapa penduduk Tionghoa Surabaya berdinas dalam pasukan atau menjadi matamata Belanda. Keberpihakan ini nyatanya tidak hanya dilakukan etnis Tionghoa saja, banyak juga di antaranya orang-orang bumiputra (K'tut Tantri, 2006: 215-216). Menggadaikan kesetiaan bukanlah jalan yang patut ditempuh, akan tetapi kemiskinan yang membelit akibat kekacauan dari negara yang "mungkin" tidak terselamatkan menjadi satusatunya pilihan rasional. Hal ini tentu saja menuai reaksi bagi penduduk Tionghoa yang pro-Republik, hingga berujung bentrokan yang menewaskan seorang Tionghoa yang mendukung kemerdekaan. Arek-arek Surabaya yang tergabung dalam BKR (Badan Keamanan Rakyat) dan Barisan Pemuda Tionghoa segera mengambil sikap. Mereka bersama-sama menyusun daftar hitam orangorang Tionghoa yang bekerja sebagai matamata musuh (Andjarwati Noordjanah, 2010: 111). Aksi pembersihan yang dilakukan menimbulkan ketakutan bagi penduduk Tionghoa yang tinggal di kota.

Keresahan mulai memuncak ketika Surabaya diguncang pertempuran hebat pada tanggal 10 November 1945. Sebagian besar penduduk kota baik penduduk lokal maupun Tionghoa mengungsi ke wilayah selatan. Sedangkan mereka yang lebih memilih untuk tetap tinggal berada di dalam lindungan Panitia Keamanan Rakyat (PKR). Penggerak lembaga multietnis ini dipimpin oleh seorang pribumi walau kekuatan penggerak sebenarnya dalam organisasi ini adalah Tionghoa yang bernama Oei Chiao Liong. PKR merupakan suatu bentuk kerjasama antara penduduk Tionghoa dan penduduk bumiputra non politik yang berusaha menjaga keamanan dan mengurus kepentingan warga Tionghoa dan Indonesia yang tidak ikut mengungsi. Selain itu terdapat lembaga sosial non politik lain seperti Palang Merah Tionghoa yang bertugas memberikan pelayanan kesehatan kepada warga Surabaya dari berbagai etnis (Somers Heidhues, 1991: 167).

Untuk mengantisipasi bocornya informasi ke pihak musuh, para pemuda kembali melakukan pembersihan terhadap mata-mata Belanda. Dalam sebuah penggalan cerita pendek yang ditulis Idrus dengan judul Surabaya, perasaan takut tergambar jelas di benak rakyat Surabaya terhadap para pengkhianat Republik:

\begin{abstract}
"Rakyat cukup berani menghadapi meriammeriam musuh.... namun betapa takut mereka terhadap mata-mata musuh. Pemandangan yang mengerikan itu menghembus bagaikan badai di atas kota-kota dan di dalam hati kaum lelaki, meratakan segala sesuatu di jalannya baik keberanian maupun kerasionalan. Setiap orang curiga terhadap semua orang lainnya, dan untuk membebaskan diri dari siksaan pemandangan ini mereka saling membunuh" (Reid, 1996: 89).
\end{abstract}

Ketakutan berujung pada kecurigaan tersebut terbukti nyata. Seorang Tionghoa menjadi korban ketika operasi pembersihan dilakukan, dirinya dianggap sebagai matamata Belanda. Barang-barangnya disita kemudian orangnya dibakar hidup-hidup di Alun-alun Sidoarjo. Dugaan bahwa NICA menandai mata-matanya dengan tanda khusus, 
berkembang menjadi sesuatu yang tidak dapat dinalar, dimana banyak orang dibunuh hanya karena kebetulan pakaiannya mempunyai unsur-unsur warna bendera Belanda. Adakalanya isu-isu negatif maupun teror yang terjadi sengaja ditiupkan oleh pihak Belanda untuk memperkeruh keadaan. Taktik itu memang dilakukan agar sistem segregasi dan kebencian antar ras tetap tertanam diantara kemajemukan masyarakat Indonesia (Pramoedya Ananta Toer, 1998: 165). Terbunuhnya pengungsi yang dicurigai matamata Belanda membawa akibat yang buruk terhadap nama baik pemerintah dan pejuang Indonesia di Surabaya. Pihak BPRI (Barisan Pemberontak Republik Indonesia) sendiri segera mengambil tindakan dengan mengumumkan bahwa serangan terhadap warga asing tidak dibenarkan dan harus dihentikan. (Andjarwati Noordjanah, 2010: 131).

Ketika tersiarnya berita tentang proklamasi, banyak rakyat Indonesia yang tinggal di luar Jawa tidak mempercayainya. Di Sumatera Utara, faktor hubungan sosial multi-etnis dan suasana ketidakharmonisan yang terbentuk pada masa-masa sebelumnya, membuat informasi kemerdekaan menjadi simpang siur. Hanya dalam beberapa minggu, isu tersebut berkembang menjadi suatu kecurigaan antar lapisan sosial dan konflik yang bersifat vertikal dan horizontal (Reid, 1996: 111). Sikap berbeda ditunjukkan oleh penduduk Tionghoa Medan, dimana kemerdekaan tidak mendapat tanggapan serius dari dalam komunitas ini. Mereka lebih memilih diam dan menunggu hingga semuanya menjadi jelas. Pedagang-pedagang Tionghoa yang memiliki kios di pasar maupun di Pecinan memilih tutup sebagai langkah antisipasi dari tindak kriminal.

Kebenaran tentang kemerdekaan Indonesia mulai menguat ketika Mr. Teuku Mohammad Hasan tiba di Medan dengan membawa "oleholeh" dari Jakarta. Ia tidak gegabah, dialog dengan Shu Sangi Kai yang dipimpin Dr. T. Mansjoer hal pertama yang harus dilakukan, mengingat masih kuatnya otoritas yang dimiliki keenam kesultanan di Sumatera Utara. Gubernur Sumatera Utara tersebut menyampaikan pesan untuk secepatnya menyampaikan kabar kemerdekaan untuk rakyat Medan dan segera membentuk pemerintahan daerah, akan tetapi dialog tersebut tidak menemukan titik temu. Hal ini terjadi karena pada dasarnya mayoritas bangsawan Melayu menginginkan kembalinya pemerintahan Belanda di wilayah ini. T.M. Hasan mulai mendapatkan angin segar ketika dukungan penuh datang dari BKPI (Barisan Kebaktian Pemuda Indonesia) dan organorgan perjuangan lainnya (Hamdani, 2013: 145-146).

Pada masa-masa awal dimulainya revolusi sosial, penduduk Tionghoa banyak mengalami gangguan dengan alasan politik maupun ekonomi. Kelompok-kelompok ini secara teratur merampoki toko-toko dan gudanggudang milik Tionghoa sekaligus menyita barang-barang yang menurut kabar sengaja ditimbun (van Langenberg, 1990: 139). Perampokan yang berkedok "perjuangan" tersebut membuat Tjamboek Berdoeri (Kwee Thiam Tjing) angkat bicara. Lewat tulisannya ia menuturkan bahwa:

"Djamino dan Djoliteng gespuis (bajingan), marika itoe di zaman revolutie mendjadi pemboenoeh, toekang perkosa, toekang bakar 
roemah pendoedoek jang tida berdosa, toekang sembeleh korban-korbannja jang majit-majitnja kamoedian ditoewangin benzene boeat dibakar!..... Jang golongan Djamino dan Djoliteng dari bangsa apa djoega seringkali bikin moemet (pusing) kepala dari pemimpin-pemimpinnja, ini bisa dimengerti" (Tjamboek Berdoeri, 2004: 292-293).

\section{POLITIK DALAM CERPEN PAO AN TUI}

Wacana politik kental dalam kaitannya dengan posisi etnis China di Indonesia. Hal tersebut sangat tampak terutama pada masa rezim orde baru, di mana etnis China sangat dijauhkan dengan akses politik, meskipun hakhaknya tetap ada. Dalam struktur yang lebih besar, ada wacana politik Indonesia yang etnosentrik yang memandang bantuan luar negeri sebagai campur tangan dan intervensi dalam politik dalam negeri (Eriyanto, 2005: 346). Memang benar bahwa pada masa itu masyarakat kita beranggapan bahwa etnis China masih merupakan warga asing yang tidak patut mendapatkan hak-hak politik. Selain itu, Pao An Tui sebagai lembaga bentukan KNIL Belanda juga dianggap sebagai suatu bentuk intervensi asing terhadap politik Indonesia.

Akibat terjadinya kekacauan yang telah menimbulkan banyak penderitaan kepada etnis Tionghoa sebagai ekses aksi militer Belanda, timbul pemikiran sejumlah tokoh peranakan Tionghoa di Jakarta untuk mencari jalan agar kejadian serupa tidak terulang kembali. Perkumpulan Chung Hua Tsung Hui (CHTH) Jakarta memiliki inisiatif untuk mengadakan konferensi yang terdiri dari perwakilan-perwakilan $\mathrm{CHTH}$ seluruh Indonesia. Konferensi Tionghoa ini rencananya akan diadakan di Gedung Sing Ming Hui Jakarta selama tiga hari, mulai dari tanggal 24-26 Agustus 1947. Setelah melalui persidangan yang panjang akhirnya tercetuslah beberapa keputusan:

1. Pembentukan Pao An Tui (Badan Pelindung Keamanan Tionghoa)

2. Mendirikan suatu badan penyiaran resmi

3. Menyebarluaskan hasil keputusan ke dalam dan luar negeri

4. Koordinasi untuk menolong korbankorban yang akan dibentuk di setiap daerah (Sulardi, 1994: 62-63).

Tanggal 29 Agustus 1947 merupakan hari di mana Pao An Tui disahkan berdasarkan keputusan rapat perwakilan Tionghoa Indonesia yang tergabung ke dalam Chung Hua Tsung Hui Lien Ho Pan She Tsu (Badan Koordinasi CHTH Indonesia) -salah satu anggotanya ialah Kwee Kek Beng--, dan Jakarta dipilih sebagai kantor komite pusat. Keberadaan Pao An Tui -setelahnya akan digunakan kata PAT- tergantung pada berlakunya masa darurat perang yang berarti sewaktu-waktu organisasi ini dapat dibubarkan.

Beberapa hari sebelumnya Konsul Jenderal Tiongkok, Tsiang Chia Tung lewat siaran radio Batavia memberitahukan bahwa orangorang Tionghoa yang berada di wilayah pendudukan Belanda diberi kebebasan untuk mendirikan badan keamanan sendiri. Srdangkan penduduk Tionghoa yang tinggal di dalam wilayah republik jika dirasa perlu diperbolehkan membentuk badan keamanan serupa. Himbauan tersebut ditolak mentahmentah oleh pemerintah RI karena mereka yakin keselamatan etnis Tionghoa di wilayahnya terjamin dan tidak ada yang mendapat perlakuan istimewa (A.H. Nasution, 1977: 35). Selain itu masyarakat Tionghoa 
yang ada di daerah republik juga menyadari jika mereka membentuk badan keamanan sendiri, maka posisi mereka sangat tidak diuntungkan karena dapat menimbulkan salah paham dengan pihak pejuang.

Kemunculan PAT pada masa revolusi merupakan sesuatu yang istimewa di mana organisasi ini mendapat izin dari Belanda, seperti tertuang pada Keputusan Peraturan Penguasa Militer No. 516 yang ditandatangani oleh Jenderal S.H. Spoor. Ini berarti orang Tionghoa diberi keleluasaan dan di-“anak emas"-kan karena sebagian besar dari mereka mendukung dan terlibat dalam kebijakan yang diterapkan Belanda. Hal ini sebuah kewajaran mengingat pada masa ini Belanda lebih berfokus pada pemulihan keamanan dan perekonomian Indonesia yang telah lama terkoyak akibat perang. Organisasi kepolisian Tionghoa ini mendapat tugas dan wewenang untuk melindungi jiwa dan harta milik orang Tionghoa, mereka akan ikut campur dalam tugas militer apabila dibutuhkan, dan keanggotaannya terbatas pada orang Tionghoa saja, dan kadang-kadang mempunyai anggota orang Indonesia (Somers Heidhues, 1991: 172). Lewat tugas dan wewenang yang diperoleh organisasi ini terlihat jelas bahwa sejak awal Pemerintah Militer Belanda ikut campur tangan. Selain melihat seberapa besar dukungan dan afiliasi komunitas Tionghoa terhadap Belanda, secara tidak langsung tugas mereka lebih diringankan karena keselamatan hidup orang Tionghoa beserta aset-asetnya sudah terwakilkan lewat PAT. Selain itu, lembaga ini juga dapat dijadikan pasukan cadangan jika sewaktu-waktu dibutuhkan.

Keberadaan PAT pada awalnya disegani dan popular di kalangan Tionghoa. Lewat
PAT-lah orang-orang Tionghoa tidak lagi merasa terancam akan tindak kejahatan karena ada saudara sebangsa yang dapat melindungi kehidupan mereka. Setiap orang akan berjejaljejalan di pinggir jalan untuk melihat parade dan tak segan memberikan semangat bagi para "pahlawan" mereka. Semangat yang diberikan tidak hanya berupa dukungan moril namun juga dalam bentuk pemberian dana. Akan tetapi, kepopuleran PAT semakin lama semakin meredup karena beberapa faktor. Besarnya biaya yang ditanggung setiap kepala rumah tangga Tionghoa dinilai besar. Keadaan yang serba sulit membuat mereka enggan untuk memberikan bantuan lagi bagi keberlangsungan PAT. Selain itu, dari tahun ke tahun keberadaan PAT semakin bergeser dari tujuan semula. Sepak terjang PAT dirasa sudah melewati ambang batas kemanusiaan sehingga tak jarang keberadaan mereka dibenci oleh berbagai pihak. Kebrutalan yang dilakukan personil PAT ditakutkan bagi sebagian orang Tionghoa akan berubah menjadi balas dendam di kemudian hari kelak (Sulardi, 1994: 91). Mereka mengecam keberadaan PAT karena lebih condong ke pihak Belanda dan seringkali memusuhi penduduk bumiputra yang tentu saja semakin memperkeruh hubungan Tionghoa dan Republiken. Dalam cerpen Pao An Tui karya Dwicipta, kita akan menemukan korelasi dalam pernyataan Sin Liong tentang sukarnya posisi Tionghoa setelah adanya Barisan Keamanan Tionghoa:

"Kita memang serba sulit. Orang-orang di Jakarta dan kota besar lain ramai-ramai membicarakan nasib babah-babah kaya yang rumahnya terus dijarah. Dan kita merelakan diri menjadi kacung Pao An Tui. Sementara mereka, babah-babah kaya itu, yang 
menyandarkan nasib hartanya pada Pao An Tui tak pernah memikirkan nasib orang- orang miskin seperti kita, walaupun kita loyal terhadap Republik. Menjengkelkan kalau dipikir-pikir" (Dwicipta, 2005: 2).

Berbagai dukungan untuk segera melakukan pembubaran PAT di seluruh Indonesia menjadi agenda serius di kalangan Tionghoa agar keberadaan badan perlindungan ini tidak terus menerus digunakan sebagai kepanjangan tangan Belanda. Di mata rakyat dan pemerintah Indonesia sendiri sudah terpetakan secara jelas bagaimana PAT pada masa revolusi secara sikap telah memihak "tamu lama".

\section{DISKRIMINASI DALAM CERPEN PAO}

\section{AN TUI}

Diskriminasi dalam cerpen Pao An Tui secara tersurat muncul dalam kutipan berikut.

Tak ada seorang pun tetangga yang melayatnya. Ia baru saja menjejakkan kaki di Kembang Jepun ${ }^{2}$ ini setelah selama hampir dua hari merangkak-rangkak di antara desingan peluru dan menyelinap menghindari laskar-laskar perjuangan yang anti-orangorang kuning dan bermata sipit seperti dirinya. Revolusi kemerdekaan benar-benar membara di seluruh pelosok negeri. Korban berjatuhan. Tak jarang di antaranya adalah korbankorban kesalahpahaman belaka. Ia tak tahu kapan situasi perang akan berhenti. (Dwicipta, 2005: 1)

Warga etnis China di negara kita masih mendapat perlakuan diskriminasi, misalnya dengan menempatkan mereka pada wilayahwilayah khusus yang diberi label seperti Kembang Jepun. Kembang Jepun adalah nama daerah tempat khusus bermukim etnis China di Surabaya. Pengkotakan-pengkotakan seperti ini merupakan wujud nyata diskriminasi.
Tidak hanya itu, diskriminasi juga ditampilkan dalam cerpen tersebut seperti pada kutipan berikut.

Ketiga orang itu kemudian pergi mengambil cangkul dan mulai mencari tempat yang tepat untuk menguburkan jenazah. Matahari bulan Desember hilang entah ke mana. Hujan terus turun sejak semalam. Sekarang, meskipun tinggal rintik-rintik, air masih menggenangi halaman belakang. Keng Hong mencangkul tanah basah, seolah lupa kalau kepenatan telah menghajar sejak dua hari yang lalu. Setelah empat jam menggali tanpa henti, akhirnya lubang sedalam lebih dari satu meter itu berhasil dibuat. Sin Liong terpaksa memindahkan air dari lubang terus-menerus untuk memudahkan penggalian. Paman Cia menggotong mayat A Siong keluar diiringi tangisan Ling-Ling. Akhirnya tubuh remaja tanggung itu dibenamkan ke tanah dalam suasana hujan rintik-rintik. (Dwicipta, 2005: 2)

Sesuai tradisi masyarakat Jawa khususnya, pemakaman merupakan hal yang sakral, di mana biasanya melibatkan anggota masyarakat dalam pelaksanaannya. Dalam cerpen Pao An Tui tampak sangat menonjol kesan diskriminasi ditunjukkan yaitu dengan prosesi pemakaman yang hanya dilakukan oleh anggota keluarga itu sendiri. Ketidakpedulian masyarakat Jawa khususnya terhadap etnis China sangat tampak digambarkan oleh Dwicipta dalam cerpen tersebut pada masa itu.

Tidak hanya diskriminasi, kekerasan pun mewarnai keberadaan etnis China di negara kita pada masa itu, seperti tampak pada kutipan berikut.

"Ayahku selamanya membela Republik. Ia lahir di sini. Dan mati pun di sini. Tak sudi ia membela orang-orang Belanda itu. Ayahku teman baik Oei Kim Sin, pendiri Pao An Tui," kata Ling-Ling menirukan suara A Siong. 
Setelah A Siong mengucapkan kalimat terakhirnya, tiba-tiba salah satu dari kelima orang itu menarik dan menusukkan parang yang disembunyikan di selangkangannya. Ling-Ling melolong-lolong. Lebih enam kali orang itu menusuk A Siong, sampai remaja tanggung itu menjelempah di lantai. Setelah korbannya ambruk, mereka kabur dari tempat itu. Ling-Ling pingsan melihat darah berceceran melumuri tubuh anaknya. Kedua adik A Siong keluar dari kamar, ikut melolonglolong melihat tubuh A Siong. (Dwicipta, 2005: 3)

Kekerasan yang muncul adalah akibat sentimen masyarakat, khususnya pejuang pribumi yang masih menganggap bahwa $\mathrm{Pao}$ An Tui merupakan bentukan Belanda yang menjadi mata-mata. Padahal secara tersurat disampaikan dalam cerpen bahwa Pao An Tui adalah bagian dari perjuangan kemerdekaan Indonesia. Kekerasan yang muncul dibarengi dengan berbagai teror yang tampak seperti pada kutipan berikut.

"Kakak, ada seseorang mengendap-endap di luar. Apa yang harus kita lakukan," bisik Hong San. Keng Hong menghunus pedang yang selalu menemani tidurnya. "Bangunkan Sin Liong," katanya. "Sudah. Dia menunggu di samping pintu," jawab Hong San. "Mereka benar-benar meneror kita."Keng Hong mendekati pintu depan. Sin Liong membungkuk mengamati orang di luar rumah. (Dwicipta, 2005: 4)

Teror yang diamalami etnis China ini tidak hanya terjadi secara fisik, namun juga secara psikis. Pada akhirnya, tidak hanya pada masa itu, selama pemerintahan orde baru pun diskriminasi dan kekerasan terhadap masyarakat etnis China ini masih terus berlangsung.

Dwicipta menggunakan cerpen ini sebagai sarana untuk menumbuhkan kesadaran dan kepekaan kita terhadap pentingnya kerukunan dan toleransi. Bahwa keberadaan etnis China di Indonesia tidak hanya sebagai benalu, tetapi juga ikut berperan dalam proses perjuangan.

\section{SIMPULAN}

Keberadaan Pao An Tui di Indonesia tidak dapat dilepaskan dari sebuah keprihatinan orang Tionghoa terhadap keberlangsungan hidup mereka di tanah perantauan. Tidak dapat dipungkiri, orang Tionghoa kerap kali menjadi target sentimen beberapa golongan yang tidak suka terhadap orang-orang Tionghoa. Alasan masyarakat sipil juga tidak dapat dipersalahkan karena orang Tionghoa lebih diistimewakan oleh Belanda pada masa penjajahan. Hal ini ditambah oleh sikap beberapa oknum Tionghoa yang lebih proBelanda pada masa revolusi, meskipun ada juga sebagian orang Tionghoa yang jelas-jelas mendukung perjuangan Republik. Akan tetapi tetap saja kekerasan terhadap etnis satu ini berlanjut, hingga akhirnya dilakukanlah pertemuan di Jakarta di mana salah satu poinnya mendukung terbentuknya Pao An Tui atau barisan keamanan Tionghoa.

Tujuan utama dibentuknya PAT pada awalnya hanya untuk menjaga pemukiman orang Tionghoa beserta aset-aset ekonominya dari sabotase, akan tetapi ternyata pemerintah Belanda memiliki rencana lain. Dari awal sengaja pemerintah militer Belanda ikut campur tangan dalam pembentukannya dan selanjutnya mereka memanfaatkan PAT untuk berbagai kepentingan militer seperti ikut perang hingga melakukan aksi sweeping di rumah-rumah bumiputra maupun Tionghoa untuk menghalau mata-mata Republik.

Organisasi semi-militer ini pada awalnya diakui keberadaannya oleh orang Tionghoa, 
karena dengan adanya PAT daerah mereka aman. Akan tetapi karena masalah dana dan sikap PAT yang semakin hari semakin brutal, pengakuan itu mulai luntur disusul ketakutan beberapa orang Tionghoa yang tidak ingin ini menjadi ajang balas dendam dan alat bagi penguasa Belanda. PAT sendiri keberadaannya akhirnya berakhir ketika diplomasi politik antara dua negara disetujui lewat perjanjian akan dibentuknya negara Uni Indonesia-Belanda.

Wacana politik dan diskriminasi sangat tampak pada cerpen berkonteks sejarah ini. Dwicipta mencoba membangkitkan ingatan kita terhadap pentingnya toleransi dan kebersamaan dalam mencapai tujuan tertentu. Hendaknya keberadaan etnis China diakui keberadaannya sebagai bagian dari perjuangan bangsa Indonesia, khususnya dalam membebaskan diri dari belenggu penjajahan.

\section{DAFTAR PUSTAKA}

Abdulgani, Roeslan. (1973). Seratus Hari di Surabaya. Jakarta: Yayasan Idayu.

Ardianto, Elvinaro \& Erdiyana, Lukiati

Komala. 2004. Komunikasi Massa:

Suatu Pengantar. Jakarta: Simbiosa

Rekatama Media.

Berdoeri, Tjamboek . (2004). Indonesia dalam Api dan Bara. Jakarta: ELKASA.

Cribb, Robert B. (1990). Gejolak Revolusi di Jakarta 1945-1949: Pergolakan antara Otonomi dan Hegemoni. Jakarta: Grafiti.

Darma, Yoce Aliyah. (2009). Analisis

Wacana Kritis. Bandung: Yrama Widya.

Eriyanto. (2005). Analisis Wacana: Pengantar Analisis Teks Media. Yogyakarta: Lkis.
Fairclough, Norman. (2001). Critical Discourse Analysis: The Critical Study of Language. London: Longman.

Hamdani, Nasrul. (2013). Komunitas Cina di Medan dalam Lintasan Tiga Kekuasaan 1930-1960. Jakarta: LIPI Press.

Heidhues, Mary F. Somers. (1991). "Kewarganegaraan dan Identitas Etnis Cina dan Revolusi Indonesia" dalam Jennifer Cushman dan Wang Gungwu (ed.), Perubahan Identitas Orang Cina di Asia Tenggara. Jakarta: Grafiti.

K'tut Tantri. (2006). Revolusi di Nusa Damai. Jakarta: Gramedia Pustaka Utama.

Kahin, Audrey R. (1990). "Pendahuluan", dalam Audrey R. Kahin (eds), Pergolakan Daerah pada Awal Kemerdekaan. Jakarta: Grafiti.

Nasution, Abdul H. (1977). Sekitar Perang Kemerdekaan Indonesia. Bandung: Angkasa.

Noordjanah, Andjarwati. (2010). Komunitas Tionghoa di Surabaya, 1910-1946. Yogyakarta: Ombak.

Reid, Anthony J. S. (1987). Perjuangan Rakyat: Revolusi dan Hancurnya Kerajaan di Sumatera Timur. (Jakarta: Pustaka Sinar Harapan.

Reid, Anthony J. S. (1996). Revolusi Nasional Indonesia. Jakarta: Pustaka Sinar Harapan.

Ricklefs, M. C. (2008). Sejarah Indonesia Modern 1200-2008. Jakarta: Serambi.

Setiono, Benny G. (2008). Tionghoa dalam Pusaran Politik. Jakarta: ELKASA.

Sulardi. (1994). "Pao An Tui Jakarta 19471949”. Skripsi S-1, Fakultas Sastra, Universitas Indonesia. 
Toer, Pramoedya Ananta. (1998). Hoakiau di Indonesia. Jakarta: Garba Budaya.

Internet:

http://cerpenkompas.wordpress.com/2005/11/

27/pao-an-tui-1/ 